\title{
Machado lê Camões: releitura de poesia na clave do descontentamento
}

\author{
Vagner Leite Rangel 1
}

RESUMO: Objetiva-se apresentar a emulação do soneto petrarquiano num poema de Luís Vaz de Camões (1524-1580) e de Machado de Assis (1839-1908). Para tanto, recorre-se à ideia de emulação, presente nos textos críticos de Machado de Assis, para então apreciarmos "Alma gentil, que te partiste", apropriação camoniana daquele tipo de soneto, e "A Carolina", apropriação machadiana da tradição, tanto no aspecto formal (o soneto petrarquiano) quanto no aspecto conteudístico (o soneto camoniano), inspiração de "A Carolina". Hipótese principal: a forma soneto serviria ao eu-lírico camoniano para homenagear a amada, ao passo que serviria ao machadiano para anunciar a dimensão de seu infortúnio irreparável, imprimindo ao soneto um tom elegíaco. Conclusão: sob o ponto de vista quinhentista, Camões expressaria o descontentamento e encontraria a sua solução no lenitivo religioso, mas, sob o ponto de vista moderno, este será recusada por Machado, que dará, como veremos, outra solução ao problema.

ABSTRACT: The goal of this paper is to present the emulation of the petrachian sonnet in the poetry of Luís Vaz de Camões (1524-1580) and Machado de Assis (1839-1908). To do so, it is based on the classic idea of emulation, which is put forward by Machado de Assis in his critical writing and reading of universal literature. It is going to be pointed out the presence of that sonnet in the poetry of the Portuguese and the Brazilian as well. In order to do so, it will be presented a reading of "Alma gentil, que te partiste", in which Camões, emulating that type of sonnet, thinks about discontent. And then it will be presented a reading of "A Carolina", in which Machado de Assis emulates Camões's sonnet, thinking then about the same problem but under the modern point of view.

PALAVRAS-CHAVE: Emulação. Releitura. Soneto. Camões. Machado.

KEYWORD: Emulation. Reading. Sonnet. Camões. Machado.

\section{Introdução: releitura e emulação}

A partir da ideia de emulação - "Nem tudo tinham os antigos, nem tudo têm os modernos; com os haveres de um e de outro é que se enriquece o pecúlio comum" (ASSIS, 1962, v. III, p. 809) -, sintetizada em "Instinto de Nacionalidade" (1873) e desenvolvida em “A Nova geração" (1879), - “Aborrecer o passado ou idolatrá-lo vem a dar no mesmo vício" (ASSIS, 1962, v. III, p. 835) -, observaremos a presença do soneto petrarquiano

\footnotetext{
${ }^{1}$ Mestrando em Teoria da Literatura e Literatura Comparada pelo Programa de Pós-Graduação em Letras da UERJ, desenvolvendo os seguintes projetos "Entre a cruz e a espada: o autor de Ressurreição" e "Poesias completas ou páginas de assaz Melancolia?".
}

Revista Crioula USP, $\mathrm{n}^{\circ}$ 17, junho de2016 
na lírica de Luís Vaz de Camões (1524-1580) e na lírica de Machado de Assis (1839$1908)^{2}$. Nem Camões teve tudo, nem tudo teve Machado. Aquele não pôde ter pelas condições históricas, que se sobrepõem a todos os homens, este não pôde ter por causa do empréstimo formal, que lhe toma os louros da ilusão de invenção integralmente original, mas lhe dá o mérito de reler o mote e forma camonianos. Buscarei, aqui, chamar a atenção para poetização da teoria defendida por Machado de Assis: nem idolatria do passado, nem aborrecimento, mas empregá-la à medida que responde às necessidades do aqui e agora: o século XX sob os olhos do poeta Machado de Assis, isto é, as vicissitudes do homem oitocentista, ainda que tal poema tenha sido publicado no início do século passado.

O curioso é que a poética defendida e empregada pelo brasileiro, a poética da emulação, que é contrária à antinomia entre antigos e modernos, nos leva a observar que Camões, poeta quinhentista, também emulou outro poeta, Petrarca, que emulou outro poeta, Dante, enriquecendo, na intertextualidade ininterrupta do tecido literário, a literatura; esta designada, nos textos do brasileiro, por meio da metáfora do pecúlio, que vale ser retomada em sua totalidade:

Cada tempo tem o seu estilo. Mas estudar-lhes as formas mais apuradas da linguagem, desentranhar deles mil riquezas, que, à força de velhas se fazem novas, - não me parece que se deva desprezar. Nem tudo tinham os antigos, nem tudo têm os modernos; com os haveres de um e de outro é que se enriquece o pecúlio comum (ASSIS, 1962, v. III, p. 809).

Conforme os dicionários de termos literários, o escritor, poeta e político Dante Alighieri (1265-1321) foi um dos primeiros poetas “[...] a cultivar o soneto, mas coube a Petrarca (1304-1374) o mérito de lhe haver emprestado uma forma e conteúdo que se tornariam modelares para os pósteros, não só na Itália como em outros países da Europa" - explica Massaud Moisés (2013, p. 445), autor do Dicionário de termos literários. E nós veremos que o Brasil poderia ser acrescentado, naquela lista, porque Machado de Assis também cultivou o soneto petrarquiano, apesar desta forma já se encontrar sedimentada

\footnotetext{
${ }^{2}$ Aqui, registro a observação do professor João Cezar de Castro Rocha (2013), que chama a nossa atenção para o emprego voluntário da poética da emulação, no estupendo Machado de Assis: por uma poética da emulação. Nas palavras dele: “A poética da emulação equivale ao resgate moderno de práticas retóricas progressivamente abandonadas depois do advento do romantismo. Por isso, diferencio aemulatio - técnica definidora do sistema literário e artístico pré-romântico - e poética da emulação - esforço deliberadamente anacrônico, marca d'água da literatura machadiana" (ROCHA, 2013, p. 11; grifos no original).
} 
na época de Machado de Assis. Também poderíamos acrescentar que Petrarca enriqueceu o pecúlio comum, dando-lhe um arremate final. É que o soneto petrarquiano se caracteriza por duas quadras e dois tercetos, e "O último verso do soneto, porque encerrava o conceito fundamental do poema, constituía o 'fecho de ouro' ou a 'chave de ouro'” (MOISÉS, 2013, p. 445). Com Petrarca, o diamante bruto adquire uma forma lapidar. Com Camões, um certo encanto entre descontentamento e recompensa metafísica. Com Machado, nada além da física.

Apesar desta explicação derivada das palavras do autor do Dicionário de termos literários, foi Machado de Assis, autor do século XIX, quem nos chamou a atenção para o caráter histórico do desenvolvimento formal deste gênero literário. Exortação que nos leva a pensar o soneto como forma histórica que se lapidou com Petrarca e, sendo então pecúlio comum, foi apropriada por Camões, e, mais modernamente, por ele, cuja finalidade será observada adiante. É neste sentido que se pode pensar na presença do soneto petrarquiano em Camões e Machado.

Voltando ao aspecto formal, as quadras (as duas primeiras estrofes do poema, compostas de quatro versos) têm a função de anunciar o mote (tema) do soneto, que representa o conceito que será glosado pelo poeta, e os tercetos (as duas últimas estrofes do poema, compostas de três versos) têm a função de encerrar o tom da glosa poética. Os tercetos, porém, nem sempre ratificam o anunciado pelas quadras: o princípio do soneto pode apresentar um quadro, que se depreende da leitura dos versos iniciais, mas são os versos finais que determinarão a tónica daquele quadro poético, seja ele fingido de modo duplo, seja ele fingido de modo único. ${ }^{3}$ Daí o caráter lapidar do sintagma "chave de ouro", empregado por Moisés (2013, p. 445), para designar o conceito fundamental do soneto. Este expediente formal será analisado nesta releitura de poesia: o uso do soneto petrarquiano pelo poeta português, em "Alma gentil, que te partistes", e pelo brasileiro, em "A Carolina", apresentam tal dinâmica: as quadras determinam o mote, os tercetos, no entanto, encerram o conceito fundamental, determinando a tônica dos poemas. Passemos, pois, à apresentação da releitura da apropriação camoniana da referida forma, para então apresentar a releitura da apropriação machadiana da tradição, tanto no aspecto

\footnotetext{
${ }^{3}$ Refiro-me, aqui, a intrigante reflexão de Fernando Pessoa, em "Autopsicografia": "O poeta é um fingidor. /Finge tão completamente /Que chega a fingir que é dor/ A dor que deveras sente. / E os que leem o que escreve, /Na dor lida sentem bem, / Não as duas que ele teve, /Mas só a que eles não têm. /E assim nas calhas de roda/ Gira, a entreter a razão, / Esse comboio de corda/ Que se chama coração." Transcrito de "Literatura em voz alta", na gravação de Paulo Autran, programa da Rádio Batuta, do Instituto Moreira Salles: http://www.radiobatuta.com.br/Episodes/view/166.
} 
formal - o soneto petrarquiano - quanto no aspecto conteudístico - o soneto camoniano como mote.

\title{
Emulação quinhentista: Camões lê Petrarca
}

\author{
Alma gentil, que te partiste \\ Tão cedo desta vida descontente, \\ Repousa lá no Céu eternamente \\ E viva eu cá na terra sempre triste \\ Se lá no assento etéreo, onde subiste, \\ Memória desta vida se consente \\ Não se esqueça daquele amor ardente \\ Que já nos olhos teus tão puro viste. \\ E se vires que pode merecer-te \\ Alguma coisa a dor que me ficou \\ Da mágoa, sem remédio, de perder-te \\ Roga a Deus, que teus anos encurtou, \\ Que tão cedo de cá me leve a ver-te, \\ Quão cedo de meus olhos te levou. \\ (apud MOISÉS, s/d, p. 116)
}

Os versos da primeira estrofe anunciam o tom elegíaco do eu-lírico camoniano: trata-se da finitude do homem - "que te partiste / Tão cedo desta vida" -, sendo esta, a finitude, a principal razão pela qual o poeta canta o desencontro terrestre de dois corpos que se separam por causa daquele infortúnio, que é a morte da amada, cuja alma - a parte etérea do homem - é evocada por ele, o eu-lírico: "Se lá no assento etéreo, onde subiste, / Memória desta vida se consente / Não se esqueça daquele amor ardente / Que já nos olhos teus tão puro viste".

A cisão, anunciada na primeira estrofe, está instalada. E os termos empregados por Camões a denunciaram ("partiste/desta vida"), bem como o estado em que se encontra a voz poética: "cá na terra sempre triste". A cisão corpórea, no entanto, parece ser abrandada pelo lenitivo etéreo: "Roga a Deus". Na finitude corpórea, elemento material “daquele amor ardente", poesia e cosmovisão - "Repousa lá no Céu eternamente" - são aproximadas e produzem um efeito de sentido terapêutico, para o poeta (ou para a dor que o poeta finge): se a morte, que encerra o ciclo humano e o entristece, é irrevogável, a

\footnotetext{
${ }^{4}$ Como empregarei tais versos ao longo da exposição, não citarei, doravante, o autor e a página. Utilizarme-ei do mesmo expediente quando passar à exposição de "A Carolina".
} 
fé, fundamento do poema em que se a ideia de reminiscência é algo discutível, a vida eterna não o é, é o ponto de apoio do poeta, e tal apoio pode ser entendido como o referido lenitivo religioso, o antídoto. Na contramão do infortúnio terrestre, a sorte cristã.

A referida evocação da alma gentil, apresentada na primeira estrofe e efetivada na segunda, contém o fundamento lírico, parte do mote a respeito do descontentamento, além do fundamento religioso empregado pelo poeta. Se se consente alguma memória desta vida no assento etéreo, os olhos da amada, que viu naquele amor ardente, são prova da desgraça do poeta - parece dizer o eu-lírico, então, poderíamos dizer, vislumbrando um possível poeta delator do fingimento poético.

Brincadeira à parte, encontramos, de modo simétrico, a forma e o conteúdo estruturados harmonicamente. Com o final dos versos em "te" (rima "a"), a simetria das rimas, dispostas de modo paralelo na primeira e na segunda estrofe, produz um efeito monocórdico, constituindo um soneto bem estruturado e regular, porque os versos elegíacos (a letra do poema) foram enunciados e a música do poema, num único tom, enfatiza a ideia de descontentamento, imprimindo harmonia à forma petrarquiana. $\mathrm{O}$ compasso harmônico destas estrofes estende-se sobre os dois tercetos seguintes, produzindo uma estrutura harmoniosa ao mesmo tempo em que se desenvolve, com base no tom elegíaco, o pensamento expresso nas primeiras.

A partir da terceira estrofe, porém, observa-se o acréscimo de uma segunda rima, terminada em "ou”. Ela, entretanto, não tem um efeito dissonante sobre o poema. Ao contrário, nota-se que, sendo intercalada com a outra rima ("a" = "te"), se produz alternância nos tercetos. E a variante rítmica é utilizada para apresentar o conceito fundamental do poema, fechando-o de modo regular: a dor ficou, Deus te levou. A segunda rima, introduzida do meio para o fim do soneto, principia o referido processo de inversão do enunciado nos quartetos.

O desfecho dado por Camões produz um efeito de leitura curioso, porque, embora o poeta cante a dor da finitude e a crença no lenitivo religioso, os termos finais do poema privilegiam mais o sentimento de descontentamento do poeta que "a alma gentil que partiste". A dor que sobressai é a dor do poeta. Deus a levou do poeta. Tem-se a impressão, ao ler os versos iniciais, que a amada será o centro da atenção do poeta, pois a finitude da amada (A) enseja o canto elegíaco do poeta (B). Contudo, a partir da possibilidade de a alma guardar alguma reminiscência desta vida, cuja prova a amada carrega em seus olhos - "Não se esqueça daquele amor ardente / Que já nos olhos teus 
tão puro viste." -, o poeta inverte os termos das quadras iniciais. Em vez de seguir cantando sua dor em termos de A, a finitude da amada, e B, o canto elegíaco do poeta, ele os inverte: B se torna desfecho do poema, isto é, seu conceito fundamental, e A, glosa poética.

Tal efeito de sentido, que notamos na leitura da chave de ouro do soneto, encontra explicação na leitura de Ivan Teixeira (1987, p. 169): "No fundo, ele [Camões] está fazendo galanteria ao afirmar que deseja morrer para se unir a ela". O que não deixa de fazer sentido, afinal de contas, o fingimento poético camoniano parece estar mais interessado em homenagear a amada do que em morrer, o que faz jus à referida inversão de A e B em B e A. Ao mesmo tempo que tal hipótese é plausível, não podemos esquecer que a morte, do ponto de vista cristão - e quinhentista - pode ter tido um sentido oposto ao sentido contemporâneo dela. A sua face, desde a ascensão do modelo de vida burguês, tem sido higienizada. Aqui, vale abrir um parêntese para destacar a explicação de Walter Benjamin (1994, p. 207):

A ideia da eternidade sempre teve na morte sua fonte mais rica. Se essa ideia está atrofiando, temos que concluir que o rosto da morte deve ter assumido outro aspecto. [...]

No decorrer dos últimos séculos, pode-se observar que a ideia de morte vem perdendo, na consciência coletiva, sua onipresença e sua força de evocação. Esse processo se acelera em suas últimas etapas. Durante o século XIX, a sociedade burguesa produziu, com as instituições higiênicas e sociais, privadas e públicas, um efeito colateral que inconscientemente tivesse sido o seu objetivo principal: permitirem aos homens evitarem o espetáculo da morte.

Talvez as palavras de Benjamin também sirvam para explicar a inversão camoniana, talvez.

Em comparação com a emulação machadiana, acrescida das explicações anteriores, poderíamos pensar que o eu-lírico camoniano não deseja pôr num recanto o mundo inteiro, mas, sim, o seu soneto como epitáfio.

\section{Emulação oitocentista: Machado lê Camões}

\footnotetext{
Querida, ao pé do leito derradeiro em que descansas dessa longa vida, aqui venho e virei, pobre querida, trazer-te o coração do companheiro.

Pulsa-lhe aquele afeto verdadeiro
} 
que, a despeito de toda a humana lida,

fez a nossa existência apetecida

e num recanto pôs o mundo inteiro

Trago-te flores, - restos arrancados

da terra que nos viu passar unidos

e ora mortos nos deixa e separados.

Que eu, se tenho nos olhos malferidos

pensamentos de vida formulados,

são pensamentos idos e vividos.

(ASSIS, 1962, v. II, p. 658)

Observa-se a emulação do mote camoniano de saída: o vocativo "Alma gentil” é atualizado por "Querida", talvez mais pertinente ao vernáculo oitocentista. Enquanto a voz poética de Camões lamenta a perda da "Alma gentil”" que "te partiste/ Tão cedo desta vida descontente," a voz poética de "A Carolina" reconhece que "ao pé do leito derradeiro" ela "descansas dessa longa vida" - primeira mudança, portanto. E ela é notável por ser radical, se comparada ao modelo emulado. Ou seja, se o eu-lírico de Camões lamenta a morte precoce de um amor, que "Repousa lá no Céu eternamente", ao passo que ele está "na terra sempre triste", o eu-lírico de Machado, ao não optar pelo lenitivo religioso, aceita a finitude da matéria: "aqui venho e virei, pobre querida, / trazerte o coração do companheiro". Parte-se da mesma ideia, a perda da musa terrestre, mas chega-se a conclusões opostas: o primeiro crer na vida eterna da amada, e afirma o sentimento de tristeza posterior à perda, enquanto o segundo, ao descartar o refúgio eterno, acata o compasso do relógio, marcando as horas, os dias, as semanas, e os anos daquela ausência presente num sentimento que lhe "Pulsa [...] aquele afeto verdadeiro / que, a despeito de toda a humana lida, /fez a nossa existência apetecida". Na contramão da ideia contida no soneto-mote de Camões, que glosa o tema do "assento etéreo", Machado investiu na presença da ausência: se a finitude dos corpos põe inexoravelmente fim à matéria humana, ela não pode pôr fim ao tecido invisível das relações interhumanas, que "num recanto pôs [e põe] o mundo inteiro".

Apesar do empréstimo, o soneto machadiano afasta-se do camoniano já na primeira estrofe. E acentua tal afastamento, na segunda estrofe, ao evitar o tema da reminiscência em vida eterna, que é glosado na segunda e terceira estrofes daquele, para ratificar a existência humana sob a batuta do tempo cronológico - as rimas ("c" = "os") dos dois tercetos são monótonas, conotando o som sempre igual dos ponteiros do relógio, podemos inferir. Observe-se, através da leitura de tais tercetos, a monotonia das horas em 
cada sílaba poética tonificada: "arrancados/ unidos/ separados/ malferidos/ formulados/ vividos". Observe-se, também, que, enquanto o soneto camoniano precisa dos dois últimos tercetos para cadenciar a forma e o conteúdo, num ritmo engenhoso, em que as rimas " $a$ " e "b" intercalam-se na promoção duma sonoridade agradável, imprimindo aos tercetos um sentido uníssono, como em bloco, os dois últimos tercetos machadianos "quebram" com o ritmo intercalado dos quartetos (a/b/b/a - a/b/b/a), para empregar um terceiro som: "c".

O efeito de sentido desta quebra, considerando os dois tercetos finais, é a monotonia, que intensifica, por intermédio da repetição, o sentido dos versos, que informam a respeito de uma voz poética seca que parece dizer para si mesma que existe, apesar da ausência daquela companhia, que acalentava a existência ("num recanto pôs o mundo inteiro"). Companhia que, na primeira estrofe, pode ser observada no emprego das rimas "a" (companheiro) e "b" (querida). Se no universo camoniano, a cosmovisão faculta ao poeta o lenitivo religioso, no machadiano, este papel parece ser desempenhado por aquela que intitula o soneto: Carolina. Em sua eterna ausência, não há esperança ou prece, como há em Camões, mas, sim, o reconhecimento do império cronológico: “Tragote flores, - restos arrancados / da terra que nos viu passar unidos / e ora mortos nos deixa e separados".

A materialidade do mundo é insensível e irremediável. O homem oitocentista constrói castelos de apetecimentos, mas sabe que eterno é o tempo, que nos vê, e "nos viu passar unidos" - e, poderíamos acrescentar, nos verá. A sugestão tridimensional do poder da Terra, figurando o obstáculo intransponível do tempo, contribui para construção da tematização da morte da amada, nos dois últimos tercetos, ao tempo que comunica a morte figurada do eu-lírico machadiano, pois a morte dela também é, em alguma medida, a morte dele: "ora mortos nos deixa e separados". A medida desta morte lírica, que parece ser um fingimento em menor grau à proporção da verossimilhança que encerra, pode ser aferida na ausência que se faz presente no peito do poeta, mas alheia à "existência apetecida", cuja fortaleza, o castelo que punha o mundo num canto, soçobrou perante a força do tempo, que nos vê passar. Assim como o ritmo sempre inalterável do ponteiro do relógio, o emprego duma mesma rima - "c" -, nos dois últimos tercetos, sugere a imparcialidade do tempo perante a dor humana.

\section{Considerações finais: o descontentamento lá e cá}

Revista Crioula USP, $\mathrm{n}^{\circ}$ 17, junho de2016 
Em relação ao soneto de Camões, compreende-se a presença da religião, visto o tempo histórico do poeta. Devemos, porém, destacar o emprego engenhoso do lenitivo religioso, que faculta ao poeta jogar com a forma ("a" e "b") e sentido (aqui/vida; lá/morte) do poema, construindo um poema rico em harmonia e musicalidade, cuja primeira leitura pode até esconder o sentido das formas, devido à riqueza rítmica recomenda-se a releitura, para obter tal percepção.

Já em “A Carolina", escrito na segunda metade do século XIX, a compreensão se dá a partir da leitura dos textos críticos de Machado de Assis, como o trecho destacado na introdução, em que se evidencia a ideia de pecúlio (emulação). Afeito a essa ideia, símbolo do argumento de riqueza, em que tradição e inovação dariam as mãos em prol do enriquecimento da literatura, Machado apropriou-se do soneto camoniano para compor sua versão de "Alma gentil que te partistes". Ou, considerando a referida explicação benjaminiana, poderíamos concluir que ele compôs a versão moderna de “Alma gentil que te partistes"? De qualquer forma, o fundamental é ser "homem do seu tempo", 5 o que pode explicar o fato de ele ter evitado o refúgio da fé cristã, já em descrédito, encarando então a existência sem tal auxílio. Conformando-se com o prosseguir da vida como o prosseguir mecânico do relógio. Notemos, por fim, a analogia proposta, sobretudo nos tercetos, pela composição do poema, que, ainda hoje, é significativa à medida que nos remete a películas como Tempos modernos. ${ }^{6}$

Se for plausível concluir que os tercetos de Camões encerram uma melodia que remete às esperanças da solução religiosa, em que a religião em crédito na pena do poeta encontrava-se numa situação mais favorável, no que tange às Artes, o mesmo não poderia ser concluído dos tercetos de Machado, pois, conotando o compasso do relógio, somos

\footnotetext{
${ }^{5}$ Refiro-me à célebre passagem de "Instinto de Nacionalidade", em que Machado de Assis defende a superação da antinomia entre tradição e inovação: "Não há dúvida que uma literatura, sobretudo uma literatura nascente, deve principalmente alimentar-se dos assuntos que lhe oferece a sua região; mas não estabeleçamos doutrinas tão absolutas que a empobreçam. O que se deve exigir do escritor antes de tudo, é certo sentimento íntimo, que o torne homem do seu tempo e do seu país, ainda quando trate de assuntos remotos no tempo e no espaço. Um notável crítico da França, analisando há tempos um escritor escocês, Masson, com muito acerto dizia que do mesmo modo que se podia ser bretão sem falar sempre do tojo, assim Masson era bem escocês, sem dizer palavra do cardo, e explicava o dito acrescentando que havia nele um scotticismo interior, diverso e melhor do que se fora apenas superficial" (ASSIS, 1962, III, p. 804; grifo meu). Enquanto poeta defensor do pecúlio e falante da língua portuguesa, podemos dizer que Machado ainda estava em sua pátria: a língua materna, que compartilhava com Camões.

${ }^{6}$ Anoto, aqui, a proximidade cronológica entre as obras: o filme de Charles Chaplin estreou em 1936, em Nova Iorque, trinta anos após a publicação de Relíquias da Casa Velha, em que Machado de Assis publicou “A Carolina”, em 1906.
} 
remetidos ao mundo, cujo trânsito não para, a despeito de toda e qualquer dor humana. Quem para somos nós, inclusive o poeta, pois o mundo moderno e o relógio prosseguem, ao passo que nos cabe lamentar nossas perdas: "Querida, ao pé do leito derradeiro/ em que descansas dessa longa vida, / aqui venho e virei, pobre querida, / trazer-te o coração do companheiro". Assim, se o descontentamento camoniano é momentâneo à proporção que há conforto, tanto cá quanto lá; o machadiano - ou será lícito dizer o nosso? -, não é. A julgar pela imagem construída através do poema, em que o poeta parece estar diante da lápide pensando e ruminando os versos "A Carolina", não haveria conforto. Haveria descontentamento acrescido de desconforto.

Cantada em tempos diferentes, a dor não poderia deixar de ter, na lírica deles, representações díspares. Não só díspares como também igualmente válidas contemporaneamente, o que apreendemos quando olhamos o mundo a nossa volta.

\section{Referências}

ASSIS, Machado de. Instinto de Nacionalidade. In: Obra completa. 2. ed. v. III. Nova Aguiar, 1962, pp. 801-808.

A Nova Geração. In: Obra completa. 2. ed. v. III. Nova Aguiar, 1962, pp. 809836.

A Carolina. In: Obra completa. 2. ed. v. II. Nova Aguiar, 1962, pp. 658.

AUTRAN, Paulo. Paulo Autran lê Fernando Pessoa. In: Literatura em voz alta. Programa de da Rádio Batuta. Instituto Moreira Salles. Disponível: http://www.radiobatuta.com.br/Episodes/view/166 Acessado em 04 set. 15.

BENJAMIN, Walter. O narrador: considerações sobre a obra de Nikolai Leskov. Magia e técnica, arte e política Ensaios sobre literatura e história da cultura. 3 ed. Trad. Sérgio Paulo Rouanet. Obras escolhidas. Rio de Janeiro: Brasiliense, 1994, p. 197-221.

MOISÉS, Massaud. Dicionário de termos literários. São Paulo: Cultrix, 2013.

CAMÕES, Luís Vaz. In: Lírica: Luís de Camões. São Paulo: Cultrix, s/d.

ROCHA, João Cezar de Castro. Machado de Assis: por uma poética da emulação. Rio de Janeiro: Civilização Brasileira, 2013.

TEIXEIRA, Ivan. Apresentação de Machado de Assis. São Paulo: Martins Fontes, 1987. 